\title{
PEMANFAATAN CITRA SATELIT LANDSAT 8 UNTUK MEMETAKAN SEBARAN TITIK PANAS SEBAGAI INDIKASI PENINGKATAN SUHU PERMUKAAN TANAH DI KABUPATEN KUTAI TIMUR
}

\author{
(Utilization of Satellite Landsat 8 Image to Mapping Hotspot Distribution \\ for Indication of Land Surface Temperature in East Kutai District)
}

\author{
Doni Dhonanto, Nurul Puspita dan Ghais anis \\ Program Studi Ilmu Tanah, Jurusan Agroekoteknologi, Fakultas Pertanian \\ Universitas Mulaw arman, Samarinda, Kalimantan Timur \\ Penulis Koresponden : dhonanto@yahoo.com
}

Article Submitted : 12-02-2021

Article Accepted : 17-08-2021

\begin{abstract}
Transformation of land-use cause forest area decrease that will affect microclimate (weather tends heat), thus hotspot may possible to scattered in that area and raise the transformation of surface temperature. The objective of this research is to determine the indication of surface temperature in East Kutai District. The advantages of this research is to give information about hotspot area distribution based on land-use and relate between hotspot with surface temperature increase so it supposed to one of the consider to transform land-use in East Kutai District. This research was held on April until May 2019 at Laboratory of Carthography and Geographic Information System, Faculty of Agriculture, Mulawarman University. This research using calculation of Land Surface Temperature (LST) value to determine the transformation of surface temperature in East Kutai District by data analysis from Landsat-8 OLI/TIRS satellite. Hotspot area distribution adapted to map of land-use so we found the source of hotspot. The result of research show there are about 6 hotspots in land-use of plantation on 2017 and increasing of the surface temperature is not static cause by depending of rainfall in East Kutai District. Increasing of surface temperature in East Kutai District on October 2013 become $22.35{ }^{\circ} \mathrm{C}$ (for minimum temperature), whereas on May 2017 become $37.24{ }^{\circ} \mathrm{C}$ (for maximum temperature).
\end{abstract}

Keywords: Hotspot, Landsat-8, Land Surface Temperature

\section{PENDAHULUAN}

Luas wilayah Kabupaten Kutai Timur yaitu $35.747,50 \mathrm{Km}^{2}$ atau $17 \%$ dari total luas Provinsi Kaltim, jumlah penduduknya pada tahun 2017 sebesar 347.468 jiwa atau meningkat sebesar $4,16 \%$ dari tahun 2016 (BPS Kabupaten Kutai Timur, 2018).

Lahan di Kutai Timur umumnya merupakan lahan pemukiman, pertambangan, pertanian, dan perkebunan. Terjadi banyak perubahan fungsi lahan, banyak lahan yang semula merupakan lahan hutan asli berubah menjadi lahan pertanian, perkebunan, pertambangan maupun pemukiman yang pada akhirnya dapat merubah ekosistem alami.

Perubahan fungsi lahan berpengaruh pada perubahan suhu permukaan dan pembukaan lahan menjadi salah satu penyebab adanya titik panas serta kenaikan suhu permukaan. Hal ini berdampak pada ketidakseimbangan ekosistem, perubahan iklim mikro, berkurangnya habitat asli satwa 
liar, dan vegetasi sehingga mudah terjadi bencana banjir, longsor, dan kekeringan.

Tujuan penelitian adalah untuk mengetahui sebaran titik panas di Kabupaten Kutai Timur berdasarkan penggunaan lahan, mengetahui distribusi dan peningkatan suhu persebaran di Kabupaten Kutai Timur dengan analisis menggunakan Citra Landsat8 OLI/TIRS serta menganalisis data dari Citra Landsat-8 OLI/TIRS untuk memperoleh nilai suhu permukaan di Kabupaten Kutai Timur.

\section{METODE PENELITIAN}

\section{Waktu dan Tempat}

Waktu penelitian dari bulan Januari sampai dengan Mei 2019; Persiapan data dan pengolahan citra secara digital dilakukan di Laboratorium Kartografi dan Sistem Informasi Geografis, Faperta, Unmul.

\section{Bahan dan alat}

Bahan penelitian : Peta Administrasi, Peta Penggunaan Lahan, Data Titik Panas dari Satelit NOAA-18 dan Citra Landsat 8 OLI/TRS path/row: 115/59, 116/59, 116/60, $117 / 59, \quad 117 / 60$ pada bulan Mei, Juni, Oktober tahun 2013 dan bulan Maret, Mei, Juni tahun 2017.

Alat yang digunakan yaitu perlengkapan untuk analisis SIG meliputi seperangkat $\mathrm{PC}$, printer, seperangkat alat tulis, Microsoft Office (Mc. Word, Mc. Excel 2016), dan ArcGIS 10.2 dengan nomor lisensi EVA479593166.

\section{Prose dur pene litian}

Tahap pengolahan data mencakup :

1. Penguduhan citra Landsat-8 dilakukan di website resmi milik USGS yakni pada alamat URL www.glovis.usgs. Citra Landsat yang diunduh adalah citra pada path/row: 115/59, 116/59, 116/60, 117/59, 117/60.

2. Penggabungan Band (layer stacking) pada citra Landsat- 8 yakni band 10 dan 11. Untuk NDVI menggunakan kombinasi band 5-4-3 sehingga dapat diketahui nilai NDVI maksimum dan minimum.

3. Koreksi Geometrik atau rektifikasi.

4. Pemotongan Citra (subset) dilakukan setelah koreksi geometrik agar dapat diperoleh cakupan wilayah penelitian sesuai dengan area yang dibutuhkan sehingga memudahkan dalam mengerjakan di tahap selanjutnya.

5. Pembuatan Area Contoh (training area).

6. Klasifikasi Citra

Klasifikasi citra yang digunakan adalah klasifikasi terbimbing (Supervised Classification), di mana kriteria dilakukan berdasarkan penciri kelas (class signature) yang didapatkan melalui pembuatan area contoh (Riswanto, 2009).

Data dianalisis dengan perhitungan nilai Land Surface Temperature (LST) yang didapatkan dari beberapa persamaan. Nilai OLI dan TIRS pada citra band 10 dan band 11 diubah menjadi nilai radiasi Top of Atmosphere (TOA) dengan menggunakan persamaan (1).

$$
L \lambda=M L Q c a l+A L \ldots \text { (1) }
$$

Di mana :

$$
\begin{aligned}
L \lambda= & \text { TOA } \text { spectral radiance }(\text { Watts } /(\mathrm{m} 2 * \\
& \text { srad } \mathrm{mm}) \\
M L= & \text { Band }- \text { specific multiplicative rescaling } \\
& \text { factor from metadata } \\
A L= & \text { Band }- \text { specific additive rescaling factor } \\
& \text { from the metadata }
\end{aligned}
$$

Nilai $L \lambda$ merupakan nilai radiasi spektral. Nilai ini digunakan untuk mencari nilai temperatur kecerahan satelit dengan menggunakan persamaan (2).

Di mana:

$$
B T=\frac{K 2}{\ln \left(\frac{K 1}{\mathrm{~L} \lambda}+1\right)}-272.15 \ldots(2)
$$

$\mathrm{T}=$ Temperatur kecerahan satelit $\left({ }^{\circ} \mathrm{C}\right)$

$L \lambda=$ Radiasi Spektral $\left(\right.$ Watts $/\left(\mathrm{m}^{2} * \operatorname{srad} *\right.$ $\mu \mathrm{m})$ )

$\mathrm{K} 1$ dan $\mathrm{K} 2$ = Band-specific thermal conversion constant from the metadata

Penelitian ini menambahkan faktor vegetasi untuk menghitung nilai LST dengan menggunakan Normalized Difference Vegetation Index (NDVI) untuk menentukan 
nilai emissivitas permukaan bumi. Nilai NDVI berasal dari band multispectral yaitu kombinasi Band 5-4-3 sehingga didapatkan nilai NDVI maksimum dan minimum. Dengan persaman Proportion of Vegetation berikut (3).

$$
P v=\left(\frac{N V D I-N D V I \min }{N D V I \max -N D V I \min }\right)^{2}
$$

Hasil dari Proporsi vegetasi (Pv) ditambahkan dalam persamaan untuk mencari nilai emissivitas permukaan bumi (4).

$$
e=0.004 P v+0.986 \ldots \text { (4) }
$$

Di mana:

e $=$ Emissivitas

$\mathrm{Pv}=$ Proporsi vegetasi

Nilai perhitungan di atas untuk menentukan perhitungan akhir yaitu nilai LST yang menentukan temperatur potensial permukaan pada saat citra merekam permukaan. Berikut persamaan LST (5).

Di mana:

$$
L S T=\frac{B T}{1}+w *\left(\left(\frac{B T}{p}\right) * \operatorname{Ln}(e)\right)
$$

$\mathrm{BT}=$ temperatur kecerahan satelit $\left({ }^{\circ} \mathrm{C}\right)$

$\mathrm{W}=$ panjang gelombang radiasi $(11.5 \mu \mathrm{m})$ $\mathrm{p}=\mathrm{h} * \mathrm{c} / \mathrm{s}(14380)$

e $=$ emissivitas permukaan

Nilai LST yang digunakan pada Band 10 dengan asumsi tidak terkontaminasi dengan stray light. Selanjutnya hasil perhitungan dan penentuan penyaluran temperatur dikomparasi melalui tahun 2013 dan 2017, dan penyaluran area terdampak (Septiangga, 2016).

Tujuan pembuatan area contoh adalah mengindentifikasi cluster dari sejumlah pixel yang mewakili setiap kategori yang dibutuhkan dengan menentukan posisi contoh dengan bantuan peta tutupan lahan sebagai referensi untuk setiap kategori (Jaya, 2007).

\section{HASIL DAN PEMBAHASAN}

\section{Distribusi Suhu Permukaan}

Perhitungan LST pada bulan Mei, Juni dan Oktober 2013. Sedangkan untuk perhitungan LST pada tahun 2017 dilakukan pada bulan Maret, Mei dan Juni. Seperti teori sebelumnya bahwa adanya perbedaan memunculkan dinamika suhu (Septiangga, 2016). Sehingga dinamika yang terbentuk mengindikasikan adanya kenaikan suhu di Kabupaten Kutai Timur.

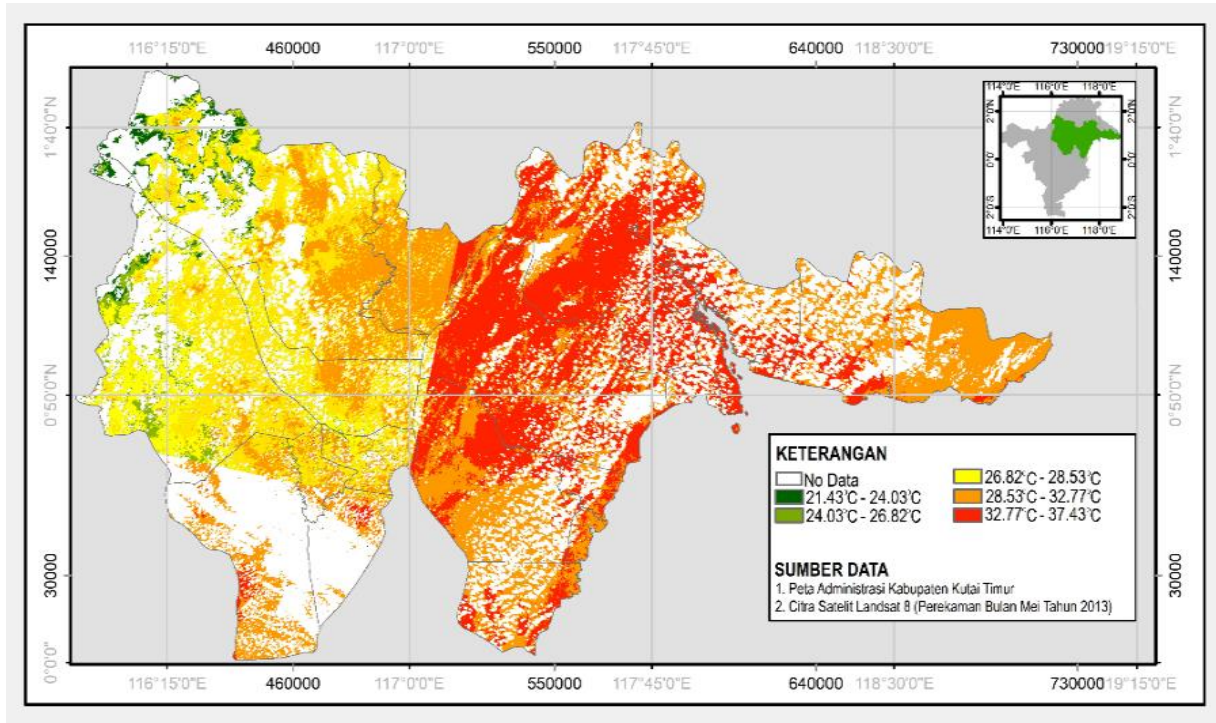

Gambar 1. Peta Distribusi Suhu Permukaan Bulan Mei 2013 


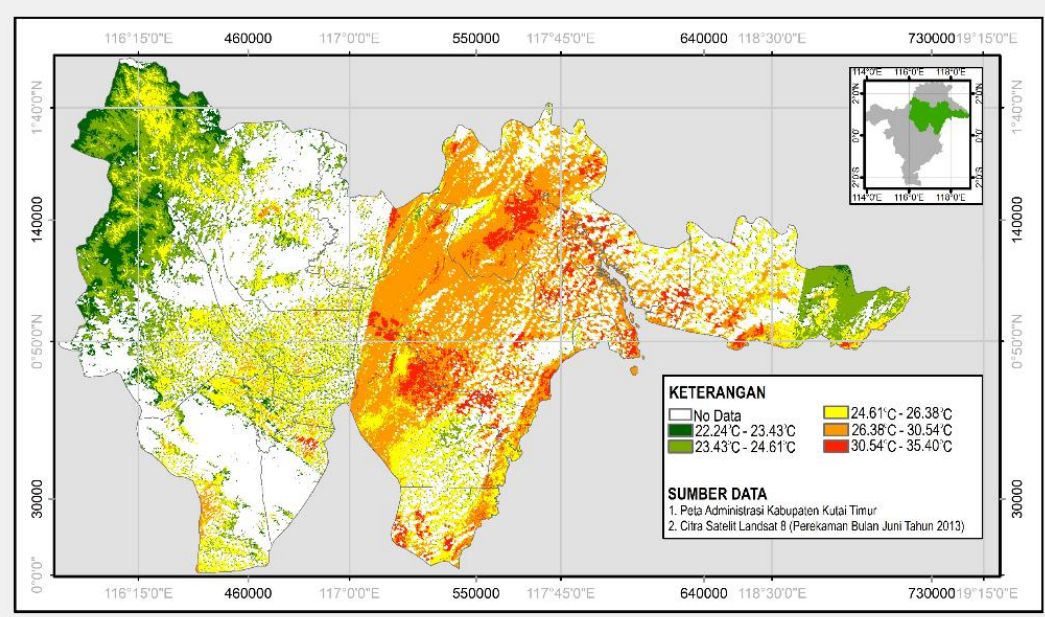

Gambar 2. Peta Distribusi Suhu Permukaan Bulan Juni 2013

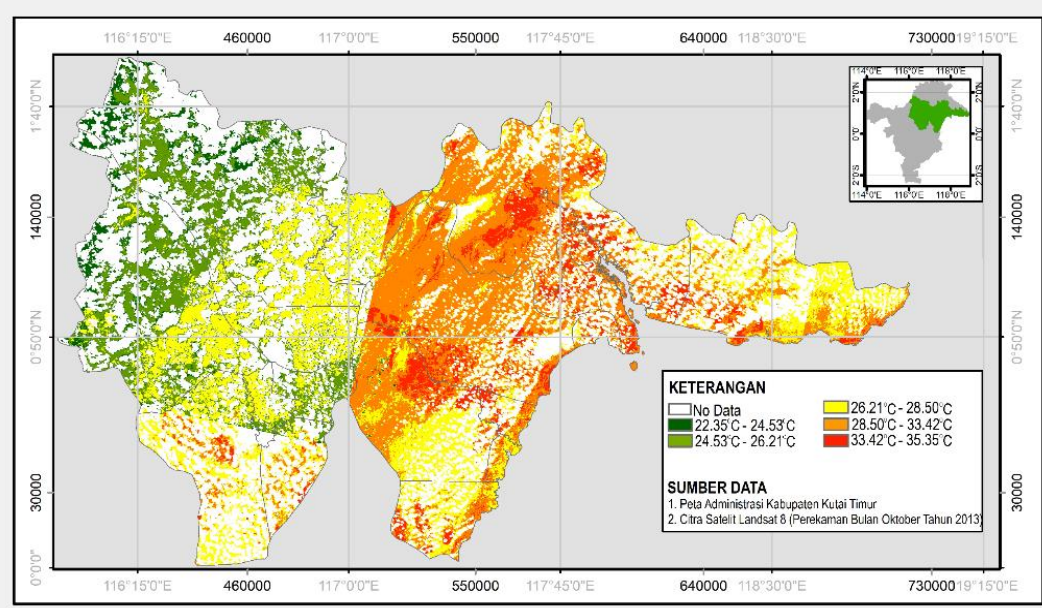

Gambar 3. Peta Distribusi Suhu Permukaan Bulan Oktober 2013

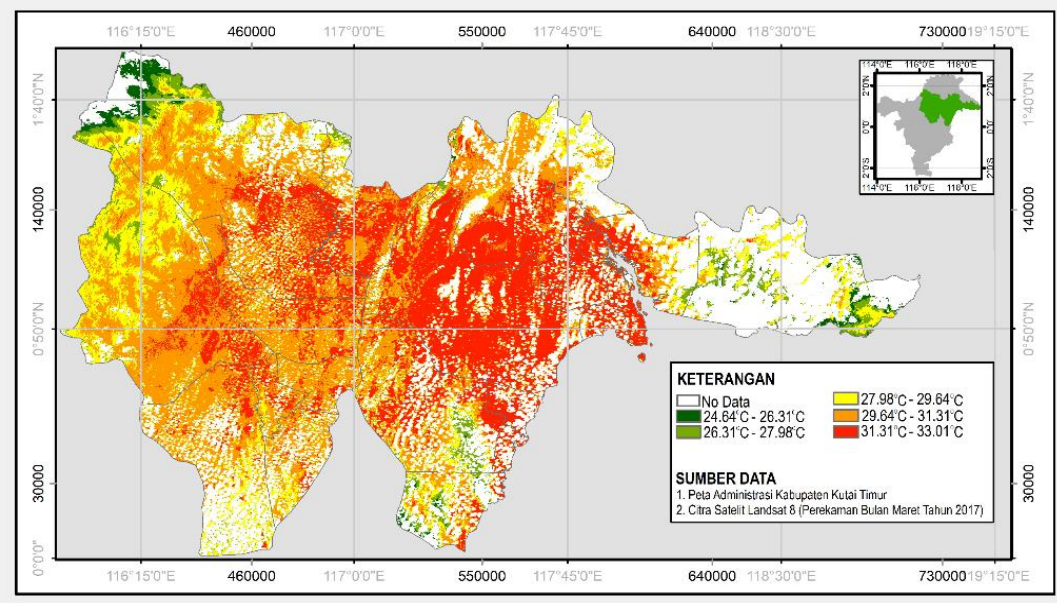

Gambar 4. Peta Distribusi Suhu Permukaan Bulan Maret 2017 
Hasil pengamatan yang telah dilakukan menggunakan Citra Landsat 8 dengan selang waktu selama 4 tahun yaitu tahun 2013 dengan tahun 2017 terlihat bahwa terjadi kenaikan suhu secara berkala namun tidak secara signifikan.

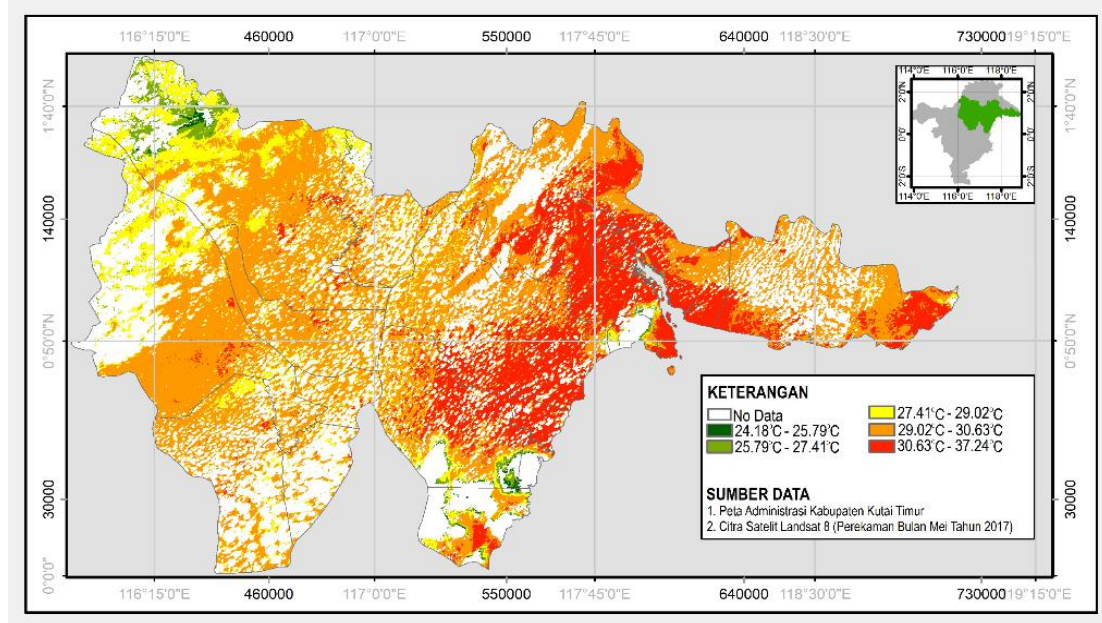

Gambar 5. Peta Distribusi Suhu Permukaan Bulan Mei 2017

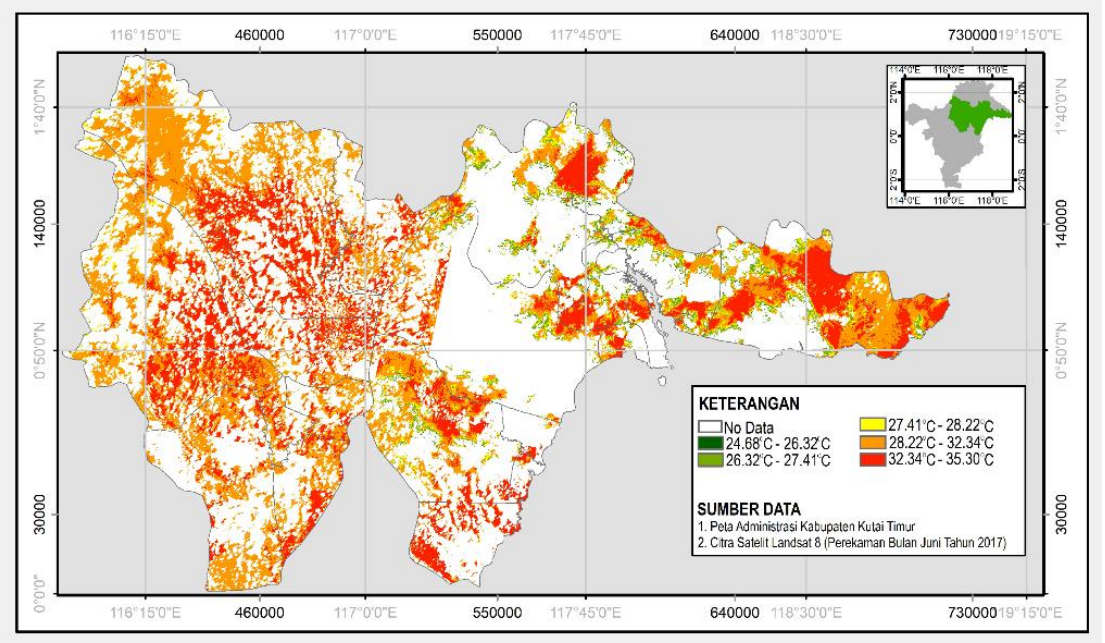

Gambar 6. Peta Distribusi Suhu Permukaan Bulan Juni 2017

Sampel bulai Mei, Juni dan Oktober untuk tahun 2013 dan bulan Maret; Mei dan Juni untuk tahun 2017. Beberapa pertimbangan dalam memperoleh sampel diantaranya adalah karena keterbatasan citra yang diperlukan, dan keberadaan awan yang dapat mempengaruhi hasil suhu permukaan yang diperlukan. 


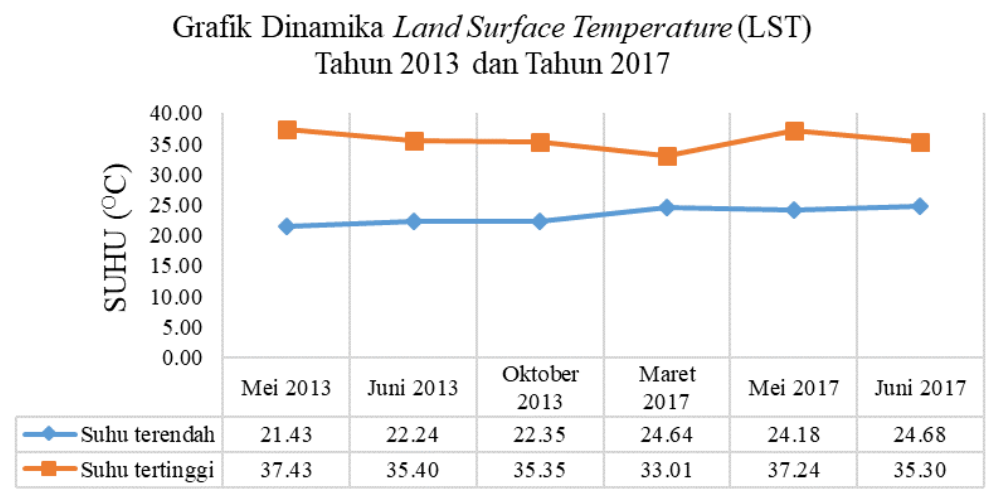

Gambar 7. Grafik Dinamika LST Tahun 2013 dan Tahun 2017

Berdasarkan hasil analisis data, diperoleh nilai perhitungan melalui piksel pada sampel dengan skala yang telah ditentukan dan disesuaikan dengan wilayah yang diperlukan. Warna merah menunjukkan adanya suhu yang tinggi, sedangkan warna hijau menunjukkan adanya suhu yang rendah pada wilayah tersebut. Peningkatan suhu minimum sekaligus penurunan suhu maksimum terjadi pula pada tahun 2013 seperti yang disajikan pada grafik menghasilkan perbandingan suhu yang berbanding terbalik.

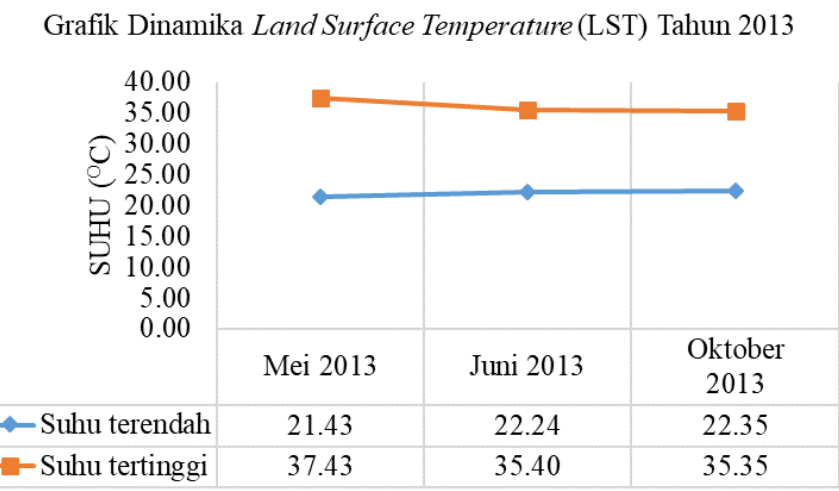

Gambar 8. Grafik Dinamika LST Tahun 2013

Hasil yang didapatkan pada grafik yaitu berbanding terbalik. Suhu maksimum dan suhu minimum pada awalnya diperkirakan akan memperoleh data yang berbanding lurus. Hal ini kemungkinan karena terjadi perubahan iklim pada tahun 2013. Namun terjadi peningkatan secara terus-menerus (konstan) pada suhu minimum meskipun tidak terlalu signifikan. Diperoleh suhu minimum yang semula pada bulan Mei sebesar $21.43{ }^{\circ} \mathrm{C}$ meningkat pada bulan Juni sebesar $22.24{ }^{\circ} \mathrm{C}$ lalu puncak peningkatan suhu minimum pada bulan Oktober menjadi sebesar $22.35^{\circ} \mathrm{C}$. 


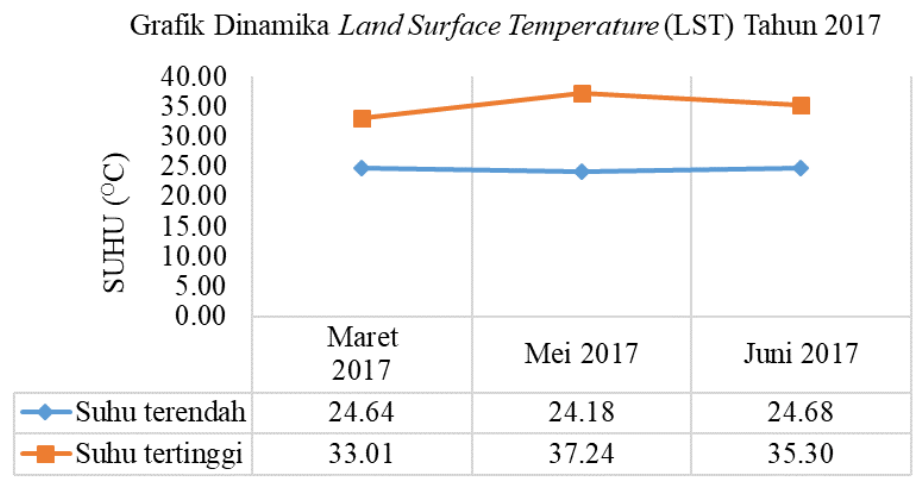

Gambar 9. Grafik Dinamika LST Tahun 2017

Terjadi peningkatan suhu maksimum, pada bulan Maret yang suhu awalnya sebesar $33.01{ }^{\circ} \mathrm{C}$ meningkat pada bulan Mei menjadi sebesar $37.24{ }^{\circ} \mathrm{C}$, tetapi terjadi penurunan pada bulan Juni menjadi sebesar $35.30{ }^{\circ} \mathrm{C}$. Suhu minimum mengalami penurunan pada bulan Mei yang semula pada bulan Maret $24.64{ }^{\circ} \mathrm{C}$ menjadi sebesar $24.18{ }^{\circ} \mathrm{C}$ pada Mei dan terjadi kenaikan pada Juni menjadi sebesar $24.68^{\circ} \mathrm{C}$.

\section{Hubungan Antara Titik Panas dengan Penggunaan Lahan}

Persebaran titik panas pada tahun 2013 tidak terdeteksi atau dikatakan tidak ada persebaran titik panas. Seperti yang ditampilkan pada Gambar 10. Persebaran titik panas pada tahun 2017 terdapat pada penggunaan lahan berupa hutan, perkebunan, tanah terbuka, semak belukar, belukar rawa seperti pada Gambar 11. Sebaran titik panas dengan menggunakan titik koordinat disajikan pada Tabel dibawah ini.

Tabel 1. Penggunaan Lahan, Koordinat dan Kecamatan Sebaran Titik Panas Tahun 2017

\begin{tabular}{|c|c|c|c|c|}
\hline \multirow{2}{*}{ No. } & \multirow{2}{*}{$\begin{array}{c}\text { Penggunaan } \\
\text { Lahan }\end{array}$} & \multicolumn{2}{|c|}{ Koordinat } & \multirow{2}{*}{ Kecamatan } \\
\hline & & $\mathrm{X}$ (meter) & $\mathrm{Y}$ (meter) & \\
\hline 1. & $\begin{array}{l}\text { Hutan } \\
\text { Sekunder }\end{array}$ & 527817.56 & 60792.13 & Rantau Pulung \\
\hline 2. & $\begin{array}{l}\text { Hutan } \\
\text { Sekunder }\end{array}$ & 510568.97 & 128215.21 & Kong Beng \\
\hline 3. & $\begin{array}{l}\text { Hutan } \\
\text { Sekunder }\end{array}$ & 501112.65 & 86213.49 & Telen \\
\hline 4. & $\begin{array}{l}\text { Hutan } \\
\text { Sekunder }\end{array}$ & 538945.42 & 46976.16 & Rantau Pulung \\
\hline 5. & $\begin{array}{l}\text { Hutan } \\
\text { Sekunder }\end{array}$ & 521693.03 & 144795.46 & Kong Beng \\
\hline 6. & Hutan Primer & 431691.44 & 135738.95 & Busang \\
\hline 7. & Hutan Primer & 455505.21 & 168010.19 & Wahau \\
\hline 8. & Perkebunan & 501112.57 & 113846.07 & Wahau \\
\hline 9. & Perkebunan & 474409.55 & 95056.68 & Telen \\
\hline 10. & Perkebunan & 593461.03 & 107225.85 & Kaubun \\
\hline
\end{tabular}




\begin{tabular}{|c|c|c|c|}
\hline 11. Perkebunan & 479972.85 & 97819.65 & Telen \\
\hline Perkebunan & 476632.64 & 38685.78 & Muara Bengkal \\
\hline Perkebunan & 472181.81 & 43107.14 & Muara Bengkal \\
\hline Semak Belukar & 597912.95 & 103136.87 & Kaubun \\
\hline 15. Semak Belukar & 448818.04 & 89532.30 & Busang \\
\hline 16. Semak Belukar & 477190.68 & 86214.04 & Telen \\
\hline 17. Semak Belukar & 498887.49 & 131530.95 & Kong Beng \\
\hline 18. Tanah Terbuka & 441023.68 & 18790.92 & Muara Ancalong \\
\hline 19. Tanah Terbuka & 439355.12 & 34597.48 & Muara Ancalong \\
\hline 20. Belukar Rawa & 552855.72 & 27633.467 & Teluk Pandan \\
\hline
\end{tabular}

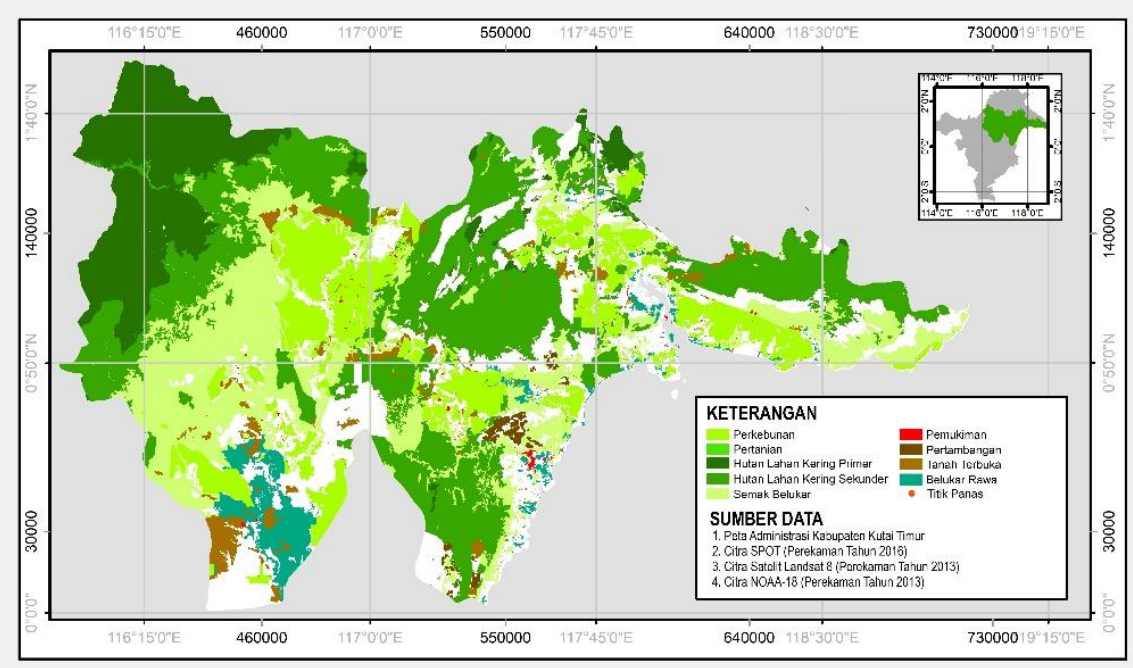

Gambar 10. Peta Sebaran Titik Panas Tahun 2013 Berdasarkan Penggunaan Lahan

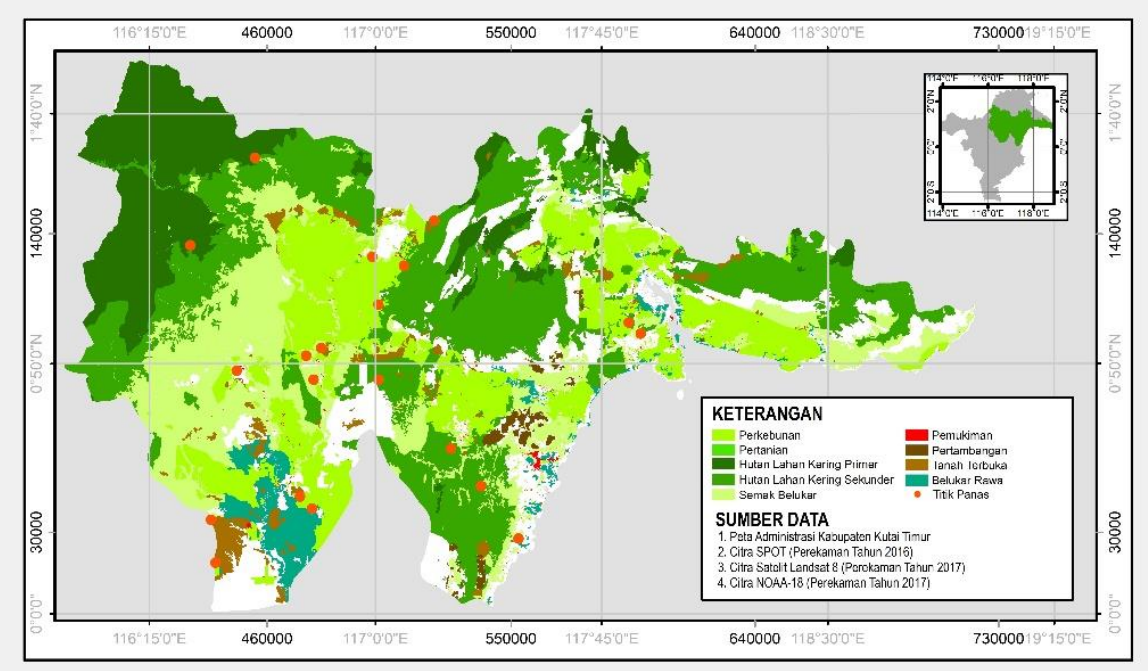

Gambar 11. Peta Sebaran Titik Panas Tahun 2017 Berdasarkan Penggunaan Lahan 
Persebaran titik panas pada tahun 2017 terjadi pada 20 titik, dan paling banyak ditemukan pada lahan perkebunan yaitu sebanyak 6 titik. Sebaran titik panas terdapat pada 4 (empat) kecamatan yaitu Kecamatan Telen (2 titik), Kecamatan Kaubun (1 titik), Kecamatan Muara Bengkal (2 titik), dan Kecamatan Wahau (1 titik). Kemunculan titik panas pada penggunaan lahan perkebunan terjadi akibat aktivitas penyiapan lahan. Hal ini sesuai dengan pernyataan Geiger et al. (1995), bahwa faktor penentu sifat dan karakteristik iklim mikro di hutan adalah radiasi matahari. Besarnya sinar matahari yang sampai pada permukaan tanah di bawah tegakan ditentukan oleh umur dan jenis tanaman, percabangan, dan bentuk tajuk.

Persebaran titik panas pada penggunaan lahan hutan dan lahan kering sekunder berjumlah 5 titik panas. Sebaran titik panas terdapat pada 3 (tempat) kecamatan yaitu Kecamatan Rantau Pulung (2 titik), Kecamatan Kong Beng (2 titik), dan Kecamatan Telen (1 titik). Diduga bahwa kemunculan titik panas tersebut disebabkan adanya aktivitas pembukaan lahan atau penebangan, atau kepekaan jenis tumbuhan penyusun vegetasi hutan seperti pinus cenderung lebih peka terhadap panas dikarenakan kandungan resin pada bagian batang.

Persebaran titik panas pada penggunaan lahan berupa semak belukar berjumlah 4 titik panas. Sebaran titik panas terdapat pada 4 (empat) kecamatan yaitu Kecamatan Kaubun (1 titik), Kecamatan Busang (1 titik), Kecamatan Telen (1 titik), Kecamatan Kong Beng (1 titik). Kemunculan titik panas pada semak belukar terutama saat musim kemarau, apabila terdapat sumber api sedikit saja, dapat mengakibatkan kebakaran yang hebat (Januarisky, 2012).

\section{Hubungan Antara Titik Panas Dengan Curah Hujan}

Kemunculan titik panas pada tahun 2017, paling banyak terjadi pada bulan
Agustus, titik panas pada bulan Pebruari 2017 yang muncul sebanyak 2 titik dengan curah hujan sebesar $257.32 \mathrm{~mm} /$ bulan. Terjadi penurunan curah hujan pada bulan Maret menjadi $251.07 \mathrm{~mm} /$ bulan dengan jumlah titik panas sebanyak 1 titik. Kemudian, pada bulan April 2017 terjadi peningkatkan intensitas hujan menjadi $278 ., 70 \mathrm{~mm} / \mathrm{bulan}$, kemunculan titik panas menjadi sebanyak 3 titik.

Titik panas pada bulan Juli 2017 sebanyak 3 titik dengan kondisi curah hujan sebesar 200,19 $\mathrm{mm} / \mathrm{bulan}$. Terjadi penurunan intensitas curah hujan pada bulan Agustus menjadi 185,52 mm/bulan dengan adanya kenaikan jumlah titik panas menjadi sebanyak 7 titik. Pada bulan September, intensitas curah hujan turun menjadi 180,41 $\mathrm{mm} / \mathrm{bulan}$ dengan jumlah titik panas menjadi 2 titik. Kemudian, pada bulan Oktober dengan curah hujan paling rendah sebesar 154,15 $\mathrm{mm} /$ bulan ditemukan titik panas sebanyak 3 titik. Berdasarkan uraian di atas terdapat hubungan yang berbanding terbalik antara curah hujan dan adanya titik panas.

\section{Hubungan Antara Titik Panas Dengan Suhu Permukaan}

Titik panas berhubungan dengan penggunaan lahan serta curah hujan yang ada. Data suhu permukaan ini digunakan sebagai data masukan dalam model perhitungan salah satunya adalah untuk mendeteksi kebakaran di permukaan bumi sebagaimana disampaikan oleh Coll, et. al (1994). Menurut Tjajaningsih, et. al (2005), suhu pada titik panas dapat dihasilkan berdasarkan nilai suhu kecerahan (Brightness temperature) yang terdapat pada Analisis Suhu Permukaan.

Kelemahan dari penentuan titik panas ini adalah tidak diketahuinya suhu permukaan pada daerah sekitarnya sehingga tidak diketahui adanya pengaruh dari perubahan penggunaan lahan terhadap suhu permukaan. Sehingga, analisis perhitungan suhu permukaan sangat membantu untuk melihat pengaruh pemanasan permukaan 
bumi dari tahun ke tahun. Berdasarkan pembahasan di atas dapat diketahui bahwa adanya hubungan yang berbanding lurus antara titik panas dengan suhu permukaan pada daerah yang memiliki sebaran titik panas.

\section{KESIMPULAN}

Tidak ada persebaran titik panas pada tahun 2013, sedangkan pada tahun 2017 terdapat 20 titik panas. Persebaran titik panas paling banyak terjadi pada tahun 2017 yaitu pada penggunaan lahan perkebunan (sebanyak 6 titik). Terjadi peningkatan suhu permukaan pada bulan Oktober tahun 2013 menjadi sebesar $22.35{ }^{\circ} \mathrm{C}$ (untuk suhu minimum), sedangkan pada bulan Mei tahun 2017 sebesar $37.24{ }^{\circ} \mathrm{C}$ (untuk suhu maksimum).

\section{DAFTAR PUSTAKA}

Badan Pusat Statistik. 2018. Kutai Timur dalam Angka 2018. BPS Kabupaten Kutai Timur. Kutai Timur. 237 hlm.

Coll, C., Caselles, V. \& Schmugge, T.J. 1994. Estimation of Land Surface Emmisivity Differences in the SplitWindows Channels of AVHRR. Remote Sensing of Environment, 47, $1-25$.

Darmanto, D., dan Sudarmadji. 1997. Dampak Hidrologis Perubahan Penggunaan Lahan di Kawasan Utara Yogyakarta. Jurnal Manusia dan Lingkungan, No.12 Th. IV : 25 - 40.

Dunggio, M. F., \& Wunarlan, I. 2013. Pengaruh Alih Fungsi Lahan Terhadap Perubahan Iklim: Studi Kasus Kota Gorontalo. Jurnal Teknik.

FAO. 1976. A Framework for Land Evaluation, FOA Soil Bull. Soil Resources Management and Conservation Service Land and Water
Development Division. FAO Soil Bulletin No. 52. FAO-UNO, Rome

Geiger, R., R.H. Aron, and P. Todhunter. 1995. The Climate Near The Ground. Fifth Edition. Friedr. Vieweg and Sohn Verlagsgesellschaft $\mathrm{mbH}$, Wiesbaden, Germany

Harjadi, B. 2009. Monitoring dan Evaluasi Daerah Aliran Sungai dengan Penginderaan Jauh dan Sistem Informasi Geografis. Forum Geografi. Vol. 23, No. 2, Desember, 139-152.

Januarisky, Hanna A. 2012. Pola Sebaran Titik Panas (Hotspot) dan Keterkaitannya Dengan Perubahan Penggunaan Lahan. Skripsi. Fakultas Pertanian Institut Pertanian Bogor. Bogor.

Jaya INS. 2007. Analisis Citra Dijital: Perspektif Penginderaan Jauh untuk Pengelolaan Sumberdaya Alam. Bogor (ID): Institut Pertanian Bogor.

Riswanto E. 2009. Evaluasi Akurasi Klasifikasi Penutupan Lahan Menggunakan Citra Alos Palsar Resolusi Rendah, Studi Kasus di Pulau Kalimantan. Skripsi. Bogor (ID): Institut Pertanian Bogor.

Septiangga, B., Juniar, R. M. 2016. Aplikasi Citra Landsat 8 Untuk Penentuan Persebaran Titik Panas Sebagai Indikasi Peningkatan Temperatur Kota Yogyakarta. Jurnal. Departemen Geografi Lingkungan Fakultas Geografi Universitas Gadjah Mada. Yogyakarta. 